This is a post-peer reviewed, pre- copy edited version of an article published in Journal of Youth Studies. The definitive publisher-authenticated version:

Laverty, L, Robinson, J. Holdsworth, C. (2015) Gendered forms of responsibility and control in teenagers' views of alcohol Journal of Youth Studies

is available online at DOI: $10.1080 / 13676261.2014 .992325$ 


\section{Gendered forms of responsibility and control in teenagers' views of alcohol}

Louise Laverty ${ }^{1}$, Jude Robinson ${ }^{1}, \&$ Clare Holdsworth²

${ }^{1}$ School of Sociology, Social Policy, and Criminology, University of Liverpool

${ }^{2}$ School of Physical and Geographical Sciences, Keele University

Corresponding author:

Louise Laverty, Room 1.19, School of Law and Social Justice,

Dept of Sociology, Social Policy and Criminology, Eleanor Rathbone Building,

Bedford Street South, Liverpool L69 7ZA.

Tel: 01517943007

Email: 1.laverty@liverpool.ac.uk

Keywords: alcohol, gender, young people, responsibility, control

Declaration of interest: 
The study was funded jointly by the Liverpool Health Inequalities Research Institute

(LivHIR) and Liverpool PCT. The views expressed are those of the authors and not necessarily those of the funder.

\begin{abstract}
There has been a shift in the most recent UK Government's Alcohol Strategy (2012) from personal responsibility towards a model of shared responsibility for young people's drinking. On closer examination of the strategy however, it appears that rather than exonerating young people from blame, governance is merely extended to include wider partners. Using findings from nine focus groups with young people in Liverpool, UK, we explore who they believe are responsible for their drinking behaviours and how they learn to become 'good drinkers'. Our findings show that while teenagers' were aware of dominant alcohol related messages and maintained a moral position as responsible citizens; they also negotiated and resisted norms about teenage drinking. Although both boys and girls agreed that parents were the primary responsible authority for regulating their drinking, there was gendered disagreement about personal responsibility. The girls described how they were ultimately responsible for any adverse consequences if they drank too much whilst the boys considered a wide range of partners who would be implicated. However, unlike the girls, the boys described a willingness to either abstain or moderate their alcohol intake in order to remain in control and avoid any alcohol related trouble or harm.
\end{abstract}

Word Count: 7699 


\section{Introduction}

Underage drinking reflects adult practices by reproducing and resisting the normative ideals of adult society (Room 2001) but is portrayed as problematic in public and political discourses (Johnson 2010). Young people are often identified as the necessary subjects of alcohol control, even though research shows a mixed picture of consumption (Measham 2008). Surveys in England show increasing numbers of abstainers among young people (Bridges 2011, Fuller and Hawkins 2014, Fuller 2012, 2013) despite more young people trying alcohol. While there is concern about the volume that some young people are drinking, recent data suggests that the quantity of alcohol consumed is also decreasing (Fuller and Hawkins 2014). The continued attention by the media and policy makers on young people, despite the changing patterns of consumption, have led some to regard underage drinking as a 'moral panic' of youth (Measham 2008, Gusfield 1967). Johnson (2010) suggests that young peoples' drinking practices are intrinsically constructed as deviant, which sits at odds with young peoples' lived experiences. These mixed messages are also found in policy with young people simultaneously occupy two contrasting positions, either as being at risk, or as being $a$ risk [our emphasis] (Kelly 2000, Kelly 2003). This multiple positioning locates young people between the state (the public) and the family (the private), blurring ideas about who is responsible, and who is to blame. 
To explore how responsibility for underage drinking is attributed in policy, a useful starting point is to examine the most recent UK Government Alcohol Strategy (Secretary of State for the Home Office 2012). While the strategy reproduces many of the key elements of its predecessors, such as the focus on binge drinking (2), there is a shift from recognising responsibility as individual to a new form of shared responsibility (4). This perhaps reflects the coalition of both Conservative neoliberal agendas and Liberal Democrat social responsibility priorities in the UK political context. This shared responsibility, for all drinkers, involves the devolution from state power towards a decentralised power that involves more targeted action at local levels. This is evident in the framing of children and young people. Young people are not regarded as wholly responsible themselves for the disruption they might produce, but are part of a wider assemblage in which families, schools and other community representatives are expected to deliver effective education. Thus the promotion of localised actions for alcohol harm reduction, particularly for young people, is not just about producing self-regulating autonomous citizens, but also recognising how these behaviours are co-produced in local institutional and community settings.

The strategy highlights that 'none of this can be achieved by one agency or service alone' (Secretary of State for the Home Office 2012, 14) and involves 'collective action by individuals, communities, local agencies and industry' (6). This focus on multiple shared responsibilities indicates a move away from individualising responsibility. However as Rose (1996) in his influential paper on the rescripting of communities warns, a focus on communities as a locus for local action can represent a new form of governance. He suggests that, drawing on the work of Foucault, this representation of community results in both 'individual responsibility and community obligation' (1996, 347). More recent research critically illustrates how the idea of community, despite the ambiguous nature of the term, has been increasingly utilised in public policy since New Labour (Day 2006, Levitas 2000, 
Bulley 2013, Byrne, Kerr, and Foster 2014, Wallace 2010, 2014). While 'community' has been linked in policy to empowerment, Levitas argues that this is a 'way of expecting groups of people who are poorly resourced to pull themselves up by their collective bootstraps' (2000, 196). We should therefore be critical in how young people in the strategy are situated within this community ideology, and be aware of community being seen as an 'unproblematic good' (Bulley 2013, 270).

This paper aims to understand this changing distribution of responsibility and how this maps on to how young people themselves articulate discourses about responsible drinking. In sharing responsibility by 'empowering' other organisations the Government is reminding us that they 'cannot and should not do it all' (Fitzpatrick and Tinning 2013). By assigning responsibility broadly, everyone (and no one) is responsible, thus we become entangled in a perpetual project of proving and displaying our responsibility and respectability. These multiple scales of responsibility serve to transfer agency (Bulley 2013), but may also 'suppress the visibility of the power of the state' (Levitas 2000, 193). Here we consider first how ideas of responsibility, discipline and control are used in alcohol discourses, before examining how these ideas reflect existing research with young people.

\section{Responsibility and Disciplining Technologies}

The work of Foucault, in particular his concepts of governmentality and biopolitics (Foucault 1978, Foucault 1988, Foucault 1997), has been applied extensively in public health (Lupton 1995, Peterson 1996, Bunton 1992, Coveney and Bunton 2003, Peterson 1997, Marshall 2001, Graham 2007, Olssen 2005). Governmentality is understood as the enacting of disciplinary practices (such as screening, educating and intervention) that aim to shape the 
behaviour and conduct of individuals (Lupton 1995). In setting out norms of expected behaviour it is not simply about ascribing responsibility, but about involving citizens in the active surveillance and maintenance of responsibility. While directed at motivating individual action, biopolitics is also about managing and regulating populations (Foucault 1988). One of the ways in which populations are managed is through responsibility. Trnka \& Trundle (2014) proposes that responsibility has become a 'buzzword for the adoption and internalisation of some of the core ideals of neoliberal governance' (138). This allows those 'constructed as responsible to be managed through self-regulation and professional forms of governance' while those seen as irresponsible are subject to criminal justice and more coercive forms of governance (Kinsman 1996, 394). Simon (1994) proposes that the state is no longer about providing choice, but about 'creating the condition for responsible choices' (32). In doing so it becomes the obligation of the rational citizen to adopt these practices, with failure to do so risking blame. Galvin (2002) points out that within public health these disciplinary technologies 'serve to reify the notions of individual responsibility and personal choice within a distinctly moral framework' (127).

Deleuze (1992) extends Foucault's thinking by proposing that we have experienced a shift from discipline to control. Power is no longer held within enclosed institutions, such as disciplinary power, but rather has become a more fluid modulation. Hardt and Negri (2000) interpret this society of control as "that society in which mechanisms of command become ever more democratic, ever more immanent to the social field, distributed throughout the brains and bodies of the citizens' (23). For Deleuze, the society of control means that we are tied into a perpetual project of the self (1992) This is readily applied to health, as optimum health is not a known, fixed, achievable end goal, but something that has to be continually worked on and managed (Greco 1993, Crawford 1984, Lupton 1995). Through the lens of the society of control we can propose that within the strategy the assemblage of responsibilities 
the buck does not stop at the individual. Nor is it held within the fixed organisations listed in the strategy. Rather we suggest that responsibility is held at different levels to include: individual, family, community, school, local authority. These are not fixed, but rather that they are fluid, mobile and able to be modified.

To look more closely at responsibility and control in alcohol discourses we will return briefly to the UK Government Alcohol Strategy as the most recent policy document. This provides a platform to examine how ideas of responsibility and control are used to claim that there is a normal safe way to drink (Cherrington, Chamberlain, and Grixti 2006), with consequences for those (including young people) who deviate (Szmigin 2008). In the strategy the target population outlined is binge drinkers. The construction of the binge drinker is as a means of distinguishing between good (responsible) and bad (irresponsible) drinkers. Within the strategy 'good' drinkers are responsible citizens who: a) do not consume large amounts of cheap alcohol, b) do not drink in public spaces and therefore, c) do not cause stress and cost on local services. In contrast 'bad' drinkers drink cheap booze, drink in public spaces, are antisocial in causing harm to others, and misuse local services. They are irresponsible and deviant because they have lost control of their body in a public way (Anderson 2014, Becker 1963). Indeed the greatest risk is 'the risk of losing the calculating subjectivity that is necessary for governing oneself in a neoliberal paradigm and monitoring one's own risks' (Moore and Valverde 2000, 526).

Public health practices 'privilege a body that is contained, under the control the will' (Lupton 1995, 131). Those who have lost control are understood as unable or unwilling to manage their own risk and are therefore in need intervention (Rose 1996). The strategy makes clear that as a consequence of loss of control, drunk citizens risk waiving their rights, 
through two specific measures. First, there is a proposal that drunken patients in Accident and Emergency departments in hospitals may be refused treatment. Second, that through enforced sobriety sentences (Secretary of State for the Home Office 2012, 14) drunk citizens will be coerced into a program of surveillance and management. Drinkers who become drunk will become excluded through their unwillingness to cooperate with the demands of the control society (Rose 1996). This is emphasised through the reiteration that drinking alcohol is not a right, and that the mind needs training in order to have control and discipline over the body. Recognising this focus on control and surveillance, it is perhaps unsurprising that in contrast to previous strategies which have been published by the Department of Health, the recent policy was coordinated and published by the Home Office. Therefore there is more of a focus on criminal justice (and relevant partners such as the police) rather than health (Ward 2012, McCambridge 2012).

Responsibility and control in accounts of young people's drinking

Although responsibility is not often the explicit focus of alcohol research with young people, it has continued to appear as an important theme in accounts. One of the most compelling findings from existing research about young people's drinking is that notions of responsibility and control are gendered (Griffin 2009, Rúdólfsdóttir and Morgan 2009, Measham 2002). While gender differences in consumption are becoming less significant, associated with an increase in young women's drinking, alcohol continues to be a key issue in the construction of gendered identities. It is important to consider how young people's drinking practices are influenced by wider media representations (Anderson et al. 2009, Gordon, Hastings, and Moodie 2010) which are highly gendered (Atkinson, Kirton, and Sumnall 2012, Day, Gough, and McFadden 2004). Young women in particular were keenly 
aware of the contested status of their drinking and the need to present themselves as aware of responsibility discourses (Measham 2004, Griffin 2009, Rúdólfsdóttir and Morgan 2009). Sheehan's (2001) study of 14-16 year old young women demonstrated that responsibility transgressed from neoliberal understandings of responsibility. The young women demonstrated responsibility through their harm minimisation techniques, of remaining in control, and the role and duties of friendship in looking after each other (Sheehan 2001). This is echoed in a number of other studies showing that young people take responsibility for supervising and intervening in friends drinking (Johnson 2010, Jørgensen et al. 2007).

Research has suggested that concerns about control are also particularly gendered amongst young people. While young men's accounts of drinking discuss the loss of control with bravado and stories of entertainment, often young women's' drinking is more about the 'controlled loss of control' (Measham 2004). Harnett (2000) found amongst his sample of young white men in London that experiencing the adverse effects of drinking were treated as a normal experience in adolescence. Knowing and being able to manage their limit was a key part of demonstrating heterosexual masculinity. However, amongst the youngest group there was concern that the loss of control through alcohol could be risky and unsafe (Harnett et al. 2000). For young women, staying within the boundaries of traditional femininity involved self-policing and self-restraint (Griffin 2009, Rúdólfsdóttir and Morgan 2009).

In summary, responsibility and control can be seen to key ideological frameworks in discussions around alcohol. Responsibility is constituted through different spheres, it is not just about the individual and what he/she does, but that this individual is scripted within particular contexts. Attempts to reframe responsibility as shared may still lay the burden on the individual. Yet the alcohol strategy also assumes that we all present responsibility from 
the same perspective. Research with underage drinkers demonstrates that responsibility is a fluid and negotiable concept, although recognised within a neoliberal framework. Gender is particularly significant in how young people present themselves as (ir)responsible and in control when drinking. Previous research has tended to focus on how responsibility is negotiated in regard to subjective experiences of drinking, this paper adds and extends this research by examining who young people see as responsible in terms of their alcohol consumption and related behaviour.

\section{Methodology}

The data we present here is drawn from a wider project, 'Understanding attitudes to alcohol consumption in secondary school communities in Liverpool', which aimed to explore young people's, parents', and teachers' views of how the wider social and cultural environment might influence young people's perceptions of alcohol use and prevention messages. In collaboration with the Liverpool Healthy School Team six state funded secondary schools participated in the study which included one girls' school, two boys' schools and three mixed schools. The schools were part of three Neighbourhood areas of Liverpool chosen for their similar composition (similar number of wards and population) with pockets of relative affluence and disadvantage. Single sex focus groups were conducted in each school resulting in a total of nine focus groups with approximately five to nine pupils in each group. Focus groups were used as a participatory method to explore the different ideas and reflections on the topic (Barbour 2008). Children and young people frequently draw on personal experience and knowledge of their immediate social groups rather than abstract theories around health (Backett-Milburn, Cunningham-Burley, and Davis 2003). As such, focus groups were considered an appropriate method, allowing for social interaction and 
debate amongst peer groups, which can be useful in encouraging critical discussion amongst disempowered populations (Barbour 2008, Kitzinger 1995, Hyde et al. 2005). In addition focus groups have successfully been used with young people to discuss sensitive health related behaviours, such as drinking behaviour (Johnson 2010), smoking (Robinson 2010), and drug use (Amos 2004).

The focus groups took place in the schools between October 2010 and May 2011 and were facilitated by one of the female authors (X). A single year cohort was chosen for the study after discussion with the local Healthy Schools team who suggested that this would ensure that pupils had experienced the same amount of information about health behaviours through the PHSE programme. In addition, national surveys have estimated that approximately $30 \%$ of 13 year olds and $50 \%$ of 14 year olds reported trying alcohol (Fuller and Hawkins 2014) and as such were considered a suitable group of young people who may have some experience of alcohol use, but may not be regular drinkers. Therefore all of the young people in Year 9 (age 13-14) were given information sheets and consent forms about the study by the named school contact a week prior to the focus groups. They were also given information sheets to give to their parents/carers with details of the named school contact and the research team to report any concerns or to opt-out their child from the study. At the start of each group there was a discussion of informed consent, assurances of anonymity and group rules around disclosure. Written consent was then obtained and further information sheets were distributed at the end of the groups with contact details for local and national support for concerns about alcohol use in addition to the research teams' contact information.

The discussions were audio-recorded with consent from the participants, and took place during a school lesson which typically lasted between 40 to 50 minutes. Teachers were not 
present throughout the discussions in order to provide a more informal and confidential setting. A draft topic guide was developed based on existing literature and presented to a Youth Advisory Group at a local community centre prior to data collection for feedback. The resulting topic guide covered: young people's lives in and out of school, perceptions of alcohol and other health related behaviour, parental strategies around alcohol, school strategies around alcohol, and prevention messages. These were open categories which allowed young people the opportunity to contribute topics they considered important. Newspaper and magazine articles about youth drinking and NHS alcohol campaign posters were used as prompts.

58 pupils consented to take part in the study, 31 males and 27 females. The majority of the pupils were from a white background reflecting the demographics of the schools and city more widely. All of the pupils had tried alcohol often under the supervision of their family. Some groups reported a higher frequency of drinking. Therefore the results represent both anticipated and actual behaviour and expectations around future alcohol behaviour. The focus group audio-recordings were transcribed verbatim, and all names and places have been changed to preserve anonymity. All quotes are in their original form.

Analysis was on going and iterative to allow emerging themes and issues to be fed back into subsequent focus groups to test the resonance with others, and to explore any differences. The transcripts were coded on a word by word and line basis, assisted by NVivo 10.0 software and initial themes were later identified (Silverman 2013, Bazeley 2013). All transcripts and themes were reviewed by all authors and analysis codes agreed, and as the thinking about the research findings developed, some of the codes were combined and 
recombined and themes refined and developed. Ethical approval for the study was granted by the University of X Non-Invasive Procedures Ethics Committee.

\section{Findings}

During the focus group conversations, young people made continual references to the dominant discourses around alcohol such as addiction, control and responsibility, suggesting that they understand the autonomous citizen ideal. While there was universal agreement that parents were an important agent of responsibility, subtle differences emerged in how boys and girls discussed who they thought should be responsible in providing information and education around alcohol. The girls utilised and framed themselves within an adapted form of neoliberal responsibility, while the boys more closely reflected the rhetoric of the society of control. These findings are discussed in more detail below.

\section{Parental Obligation and Limits of Care}

Parental responsibility was almost exclusively framed through the concept of care, with alcohol education considered as the duty of parents. This framework, connecting responsibility to care, allowed the teenagers to make sense of, and endorse a neoliberal agenda. Their parents were fulfilling their duty in civilising the nation, but as a consequence the failure of parents is positioned as irresponsible and uncaring (Skeggs 1997). Perhaps unsurprisingly the teenagers, without exception, positioned their own parents as abstinent or 
rarely drinking (except on social occasions). In addition parents were described as largely anti-alcohol which was rationalised as both disciplinary and protective:

Zoe: My mum and dad, my dad just don't do it because it doesn't do nothing for him like, he doesn't care for it, my mum just, my mum hates it. All she goes on about is alcoholics

Abi: My mum doesn't like it. My mum works in a pub so she is like surrounded by it and like she has like a drink every now and again, and so does my dad, but if I ever came in drunk like I remember one time my brother came in drunk and they just flipped on him, they wouldn't let him go out for like three months Girls FG School 4 In discussions the teenagers suggested that parents had a duty to stay in control through

minimising their alcohol intake. However, there were more discussions of how mothers assumed parental responsibility compared to fathers such as the following discussion by the boys:

Aidan: My mum would [go to the school for advice] because she doesn't drink, so she doesn't like it, so...

Stevie: My mum would like but she does drink but then she doesn't drink that much, she only drinks like on family holidays and things

Will: My mum only drinks on like big occasions

\section{Boys FG School 3}

By constructing mothers as responsible through their moderation the teenagers in the study were attempting to portray their mothers within societal norms and expectations of a 'good mother' (Lupton and Fenwick 2001, Lawler 2000). This could also be seen in how teenagers referenced their own 'good mothers' and 'other' uncaring parents. These references to 'other' parents served as a point of comparison and a way of distinguishing appropriate and unacceptable behaviour (Holdsworth and Morgan 2007). 'Other' parents were not disciplinary and allowed the child to do what they liked. 'Other' parents were described as bad role models, and morally deficient, often going as far as describing them as 'child like' in their inability to control themselves and their bodies:

Sam: I got invited to this girl's party and like her mum lets her drink and all that because the dad died and she proper gets drunk and that, and erm, she was having a party and because she knows loads of lads there was like loads of gangs from all different areas going, and I didn't end up going but apparently two gangs had knives 
and all police and that came down and the mum was just like knocked out drunk, and she didn't have a clue about it, all the gangs were trying to get in the house and all that and she couldn't do nothing because she was drunk.

Boys FG School 4

Alcohol was seen to impair other parents by making them unable to care properly. Trnka \& Trundle (2014) argue that our understandings of responsibility need to be expanded to consider that it is often enmeshed within relationships of care and social obligations. The teenagers could be argued to be discussing responsibility by illustrating their own parents as caring, and thus the teenagers as cared for. Responsibility within a neoliberal framework of autonomy overlooks these important connections. Yet beyond the importance of parental behaviours the girls and boys articulated very different understandings of responsibility particularly with reference to individual versus collective behaviours.

\section{Neoliberal Responsibility and Choice}

The girls primarily discussed parental responsibility and their own responsibility. Girls highlighted that it was their own responsibility to manage their own bodies around alcohol. The girls often represented their maturity and responsibility by referring to their own ability to protect themselves. Echoing previous research, the girls talked about the role of alcohol as part of their wider social experience and harm reduction tactics to hide their drinking behaviour rather than abstinence. In doing so they positioned themselves as knowledgeable autonomous citizens. This was reiterated amongst all of the girls' focus groups. The girls claimed that they 'knew themselves', which was supported by claiming that they were already aware of the alcohol messages delivered in schools:

Sara: You always get told like the same stuff over and over again Lisa: I don't think that we need to know because we know what alcohol Sara: I don't think we need to know anymore because we have all took it in to you know like consideration and that. So like we know the risks and that 
They argued that teachers and parents also recognised that the girls were sensible, and trusted them. This knowledge of self was seen as something to be experienced, claiming that they wanted to learn through doing:

Jodie: Learn from your own mistakes

Kirsty: To be honest learn from your own mistakes because if you do something you never want to do ever again, it's your mistake isn't it, you have done it, you can't go back in time

Girls FG School 1

This suggests that girls were happy to assume personal responsibility and by doing so, the consequences of their actions. Feminist researchers propose that within the context of modernity and feminism young women are 'doubly constructed as ideal flexible subjects' (Harris 2004, 7). Harris (2004) further claims that discourses around choice are particularly pertinent for girls who are encouraged to take personal responsibility for making the right choices in an uncertain and changeable environment' (4). Graham (2007) argues that there are different implications linking responsibility and choice: 'the responsibility to choose good choices, second to take responsibility for the consequences of those choices, and third, being responsible for making those choices' (205). The girls were thus claiming that they had achieved what had been tasked by neoliberal messages, but were able to negotiate their own behaviour through the discourse of choice.

We propose that girls recognised that in the end drinking is about individual responsibility. Through adopting neoliberal ideas about individualism, they are also assuming that this promises them 'choice, freedom and real autonomy' (Harris 2004, 4). However, as Harris (2004) notes, these promises are constrained by context and circumstance. The alternative framework for the girls however, is with the society of control, which Rich (2012) has suggests intensifies surveillance. Using Foucault's strategies of freedom, we can 
understand the girls as negotiating the way they are governed (1997). They are trying to choose freedom over surveillance. The role of school in alcohol socialisation was particularly criticised by the girls, who felt that this role crossed the public and private boundaries:

Suzy: to be honest it's got nothing to do with the school what we do after school, Kara; they try and get involved when you are outside school don't they?

Int: So whose responsibility do you think it is?

Suzy; Our own and our moms

\section{Girls FG School 1}

Foucault suggests that the aim is to 'acquire the rules of the law, the management techniques, and also the moralities, the ethos, the practice of the self, that will allow us to play these games of power with as little domination as possible' (Foucault 1997, 298). However by adopting the neoliberal ideals of personal responsibility the girls will also be blamed for making the wrong choice. Graham (2007) suggests that personal choice carries with it a culpability leading to acceptable forms of punishment.

\section{Sharing responsibility}

In contrast to the girls, the boys discussed a range of stakeholders they considered responsible agents for alcohol use, more closely echoing the Alcohol Strategy. They were also open to receiving information and education from a variety of sources rather than simply parents (like the girls). The boys discussed the potential role of the police, footballers, experts, the Prime Minister David Cameron, the Government, local businesses, and industry in delivering education:

Lucas: I think the police need to act on it [drinking] more to be honest. Because they, like it sounds quite stupid like but they were kids as well, like ones do you know what I mean so they should know what goes on and that, so really if they are doing their job properly they should be like checking the parks on like a Friday night or whatever, or outside the off licence if there is a bunch of kids standing there...

Boys FG School 4 
While discussing this diversity of responsibilities, the boys rarely focussed on their own responsibility. This did not mean however that they were uncritical of the role of the organisations that were involved, recognising the multiple responsibilities and conflicts, while contesting that they should be doing more:

Josh: On the drink adverts they have all got now drinkaware.co.uk but they put it in possibly the smallest print and like the Southern Comfort advert and all that, they have like big alcohol 'drink alcohol' and in the corner drinkaware.co.uk just like dead tiny

Boys FG School 4

The point is that the boys did not isolate their own culpability; instead they regarded their behaviour as being shaped and regulated by others, even if these individuals and institutions did not always manifest this.

The boys discussed the importance of control, and responsibility for control through moderating alcohol intake, or even complete abstinence. This was considered a legitimate measure, particularly in relation to sporting aspirations:

Int: No you don't intend drinking?

Craig: Not drink all the time.

Ryan: Not one will pass my lips.

Int: Is that just because of sport or because you just don't like it?

Craig: I want to get into my sports, so I um don't want to drink or smoke.

Ryan: Yes but I reckon if you drink, like I think drinking is good but not to like that extent where like, you have gone off your head. If you can handle yourself and have like one or two

Joe: Now don't be wrong, when I am a bit older, I will have like one drink and that but, I won't be going over the top with it.

Boys FG School 1

As these boys discussed, being able to "handle" yourself and 'knowing your limit' were frequently endorsed as ways of being moderate drinkers by the boys in our groups. This approach to drinking requires training and self-knowledge in order to be able to manage control. Other boys circumvented this need for prior experience and experimentation with reference to alternative activities (Harnett et al. 2000, Nairn 2006) to justify their non- 
drinking to their peers. Non-drinking or minimal drinking appeared to be used to display their maturity and responsibility, and sporting aspirations and future goals were frequently employed in talking about restricting their alcohol use.

Jack: Like so if you were to start drinking now at a young age, and you have got more of a chance of becoming a pisshead. Become one of them and like not getting a job and like being dirty and ending up on the streets and that...And it's not just sport, it's the rest of your life you have got to think of.

Boys FG School 2

We would suggest that the boys are utilising a form of responsibility more closely aligned to the society of control than neoliberal individualism. The boys discussed an assemblage of responsible parties which alleviates the risk of potential blame. This risk management was articulated through managing subjectivity through control. They endorsed media and strategy messages that alcohol was seen as a risk to a potential future and made efforts to manage their bodies. This links to the idea of docile bodies, in that the boys appear to want to follow ascribed acceptable drinking practices. This docility however is not uncritically accepted, rather it is an anxious, unsteady feeling. It suggests that the boys expect future risks, and have to work continually to mitigate a risky, unknown future. The boys are working within the parameters of an ongoing 'dissolution of certainty (Woodman 2009, 251) and their restricted 'choices' about drinking cannot be separated from other very substantial unknowns related to future employment options.

Our analysis challenges previous research around drinking and teenage boys. The teenage boys in our study did not endorse a complete loss of control as evidenced by other researchers (Measham 2004, Griffin 2009, Measham 2002). Rather than the boys being under less scrutiny, and thus able to reject messages around control, in this study the boys were more willing to be advised and governed by others and their requests for drinking controls cannot be separated from other anxieties about 'the rest of your life'. In Brannen and Nilsen's 
(2002) research, they proposed that young people use different strategies to manage temporal orientations, namely; deferment, adaptability and predictability. The boys in this study seem to align with the idea of adaptability which suggests that the future is understood as a risk that has to be controlled. In contrast the girls did not articulate such a strong future narrative. The girls could be interpreted by following the idea of deferment, where uncertainty is seen as a threat which cannot be easily managed. By deferring consideration of the future, girls are focusing on a present which can be controlled and managed (Brannen and Nilsen 2002).

\section{Conclusion}

These findings provide us with a new understanding of how young people manage expectations of responsibility for alcohol. It demonstrated that although boys and girls seek to portray themselves as conforming to the responsible autonomous citizen, they achieve this in different ways. Ultimately the young people in this study recognised individual responsibility, but were able to engage with alternative criticisms of neoliberal discourses. The findings are particularly relevant given that young people are called upon to assume responsibility by modifying their own behaviour (Kelly 2000). Smith (2012) predicts that children are a target for new governmental modes of regulation, where children are considered partners in the socialisation process. It is warned that this may problematize young people who do not choose appropriately, re-inscribing disadvantage as a personal or familial failing (Graham 2007).

Our findings indicate that young people are responding to new political expressions of responsibility, but there are important differences between teenage girls' and boys' articulation of responsibility. The boys in particular expressed a model closer to the 
assemblage of responsibility proposed in the Government's Alcohol Strategy. In comparison with previous research the distinctive tone of the boys' account of responsibility, their willingness to be subject to different spheres of control and acceptance of authority has not been identified in other studies. This raises the question of why young people's articulation of responsibility is gendered, and raises an avenue for future research. One possible explanation we would put forward is that the boys associate the need for regulation of drinking with their future prospects and abstinence is justified with reference to not wanting to throw away future opportunities. In contrast the girls did not associate their drinking experiences with future aspirations. This could be seen as deferment, to which Nilsen (Nilsen 1999) explains that 'uncertainty is kept at bay by not looking too far ahead neither in time nor in space' (181182).

The need to be in control is associated with successful youth to adult transitions. The boys' enhanced sense of apprehension of future options could be interpreted as a manifestation of a crisis of masculinity (McDowell 2000). This crisis is particularly intensified in cities such as Liverpool which have experienced rapid de-industrialisation and concomitant labour market restructuring which have impacted disproportionality on young men and women. As McDowell (2000) argues the crisis of masculinity is not caused by girls' success, as in cities such as Liverpool economic restructuring limits the earning potential for both young men and women, but men are experiencing a greater relative labour market disadvantage. In previous accounts of this crisis young men's response has been associated with crime and disorder (Morgan 2006), in our focus groups the boys' articulation of control is indicative of a different response to economic restructuring and uncertainty. For these Liverpool boys future uncertainties are being negotiated through the lens of control rather than agitation. These findings resonate with critics of the 'crisis of masculinity' that query 
whether it is actual or discursive (see for example Beynon 2002). At the very least for this group of teenagers, if this is a crisis it is resulting in a gendered re-scripting of responsibility.

\title{
Acknowledgements
}

\author{
References
}

Amos, Amanda, Wiltshire, S, Bostock, Y, Haw, S, and McNeill, A. 2004. "'You can't go without a fag ... you need it for your hash'-a qualitative exploration of smoking, cannabis and young people." Addiction 99 (1):77-81. doi: 10.1111/j.13600443.2004.00531.x.

Anderson, Peter, Avalon de Bruijn, Kathryn Angus, Ross Gordon, and Gerard Hastings. 2009. "Impact of Alcohol Advertising and Media Exposure on Adolescent Alcohol Use: A Systematic Review of Longitudinal Studies." Alcohol and Alcoholism 44 (3):229-243.

Anderson, T. L. 2014. Understanding Deviance: Connecting Classical and Contemporary Perspectives, Contemporary Sociological Perspectives: Taylor \& Francis.

Atkinson, AM Kirton, A and Sumnall. HR. 2012. "The gendering of alcohol in consumer magazines: An analysis of male and female targeted publications." Journal of Gender Studies 21 (4):365-386. doi: 10.1080/09589236.2012.681180.

Backett-Milburn, Kathryn, Sarah Cunningham-Burley, and John Davis. 2003. "Contrasting lives, contrasting views? understandings of health inequalities from children in differing social circumstances." Social Science \& Medicine 57 (4):613-623.

Barbour, R. 2008. Doing Focus Groups, Qualitative Research Kit: SAGE Publications.

Bazeley, P. 2013. Qualitative Data Analysis: Practical Strategies: SAGE Publications.

Becker, Howard. 1963. Outsiders : studies in the sociology of deviance. London: Free Press of Glencoe.

Beynon, J. 2002. Masculinities and Culture. Buckingham: Ope University Press.

Brannen, Julia, and Ann Nilsen. 2002. "Young People's Time Perspectives: From Youth to Adulthood." Sociology 36 (3):513-537.

Bridges, S, Gill, V, Omole, T, Sutton, R, and Wright, V. 2011. Smoking, drinking and drug use among young people in England in 2010. edited by E Fuller. London: National Centre for Social Research.

Bulley, Dan. 2013. "Producing and Governing Community (through) Resilience." Politics 33 (4):265-275. doi: 10.1111/1467-9256.12025.

Bunton, Robin. 1992. "More than a woolly jumper: Health promotion as social regulation." Critical Public Health 3 (2):4-11. doi: 10.1080/09581599208406845. 
Byrne, Christopher, Peter Kerr, and Emma Foster. 2014. "What Kind of 'Big Government' is the Big Society? A Reply to Bulley and Sokhi-Bulley." The British Journal of Politics \& International Relations 16 (3):471-478. doi: 10.1111/1467-856X.12046.

Cherrington, Jane, Kerry Chamberlain, and Joe Grixti. 2006. "Relocating Alcohol Advertising Research: Examining Socially Mediated Relationships with Alcohol." Journal of Health Psychology 11 (2):209-222.

Coveney, John, and Robin Bunton. 2003. "In Pursuit of the Study of Pleasure: Implications for Health Research and Practice." Health: 7 (2):161-179. doi: $10.1177 / 1363459303007002873$.

Crawford, Robert. 1984. "A cultural account of "health": control, release and the social body." In Issues in the Political Economy of Health Care, edited by J McKinlay, 61103. New York: Tavistock.

Day, Graham. 2006. Community and Everyday Life: Routledge. doi:10.4324/9780203463178.

Day, Katy, Brendan Gough, and Majella McFadden. 2004. "Warning! alcohol can seriously damage your feminine health." Feminist Media Studies 4 (2):165 - 183.

Deleuze, G. 1992. "Postscript on the societies of control." October 59 (Winter):3-7.

Fitzpatrick, Katie, and Richard Tinning. 2013. "Health education's fascist tendencies: a cautionary exposition." Critical Public Health 24 (2):132-142. doi: 10.1080/09581596.2013.836590.

Foucault, M. 1988. "Technologies of the self." In Technologies of the Self: A seminar with Michel Foucault, edited by H. Gutman, and Hutton P., 16-49. Amherst: University of Massachusetts.

Foucault, Michel. 1978. The Will to Knowledge: The History of Sexuality. Edited by R Hurley. Vol. 1. Harmondsworth: Penguin.

Foucault, Michel, ed. 1997. Ethics : subjectivity and truth / Michel Foucault; edited by Paul Rabinow ; translated by Robert Hurley and others. Edited by Paul Rabinow. Vol. 1, The Essential Works of Michel Foucault 1954-1984. New York: New Press.

Fuller, E. 2012. Smoking, drinking and drug use among young people in England- 2011. Health and Social Care Information Centre.

Fuller, E. 2013. Smoking, drinking and drug use among young people in England - 2012. Health and Social Care Information Centre.

Fuller, E, and V Hawkins. 2014. Smoking, drinking and drug use among young people in England in 2013. http://www.hscic.gov.uk/catalogue/PUB14579: Health and Social Care Information Centre,

Galvin, Rose. 2002. "Disturbing Notions of Chronic Illness and Individual Responsibility: Towards a Genealogy of Morals." Health: 6 (2):107-137.

Gordon, Ross, Gerard Hastings, and Crawford Moodie. 2010. "Alcohol marketing and young people's drinking: what the evidence base suggests for policy." Journal of Public Affairs 10 (1-2):88-101. doi: 10.1002/pa.338.

Graham, Linda J. 2007. "(Re)Visioning the Centre: Education reform and the 'ideal' citizen of the future." Educational Philosophy and Theory 39 (2):197-215. doi: 10.1111/j.1469-5812.2007.00306.x.

Greco, Monica. 1993. "Psychosomatic subjects and the 'duty to be well'. personal agency within." Economy and Society 22 (3):357-372. doi: 10.1080/03085149300000024.

Griffin, C, Bengry-Howell, A, Hackly, C, Mistral, W, \&amp; Szmigin, I. 2009. "'Every time I Do It I Absolutely Annihilate Myself': Loss of (Self-) Consciousness and Loss of Memory in Young People's Drinking Narratives." Sociology 43.

Gusfield, Joseph R. 1967. "Moral Passage: The Symbolic Process in Public Designations of Deviance." Social Problems 15 (2):175-188. doi: 10.2307/799511.

Hardt, M, and A Negri. 2000. Empire. Cambridge, MA: Harvard University Press. 
Harnett, Robert, Betsy Thom, Rachel Herring, and Moira Kelly. 2000. "Alcohol in Transition: Towards a Model of Young Men's Drinking Styles." Journal of Youth Studies 3 (1):61-77. doi: 10.1080/136762600113040.

Harris, Anita. 2004. Future Girl. Young women in the 21st Century. New York, London: Routledge.

Holdsworth, Clare, and David Morgan. 2007. "Revisiting the Generalized Other: An Exploration." Sociology 41 (3):401-417.

Hyde, Abbey, Etaoine Howlett, Dympna Brady, and Jonathan Drennan. 2005. "The focus group method: Insights from focus group interviews on sexual health with adolescents." Social Science \& Medicine 61 (12):2588-2599. doi: http://dx.doi.org/10.1016/j.socscimed.2005.04.040.

Johnson, P. 2010. "You Just Get Blocked'. Teenage Drinkers: Reckless Rebellion or Responsible Reproduction?" Children \& Society. doi: 10.1111/j.10990860.2009.00288.x.

Jørgensen, Morten Hulvej, Tine Curtis, Pia Haudrup Christensen, and Morten Grønbæk. 2007. "Harm minimization among teenage drinkers: findings from an ethnographic study on teenage alcohol use in a rural Danish community." Addiction 102 (4):554559. doi: 10.1111/j.1360-0443.2006.01697.x.

Kelly, P. 2003. "Growing Up as Risky Business? Risks, Surveillance and the Institutionalized Mistrust of Youth." Journal of Youth Studies 6 (2):165-180.

Kelly, Peter. 2000. "The dangerousness of youth-at-risk: the possibilities of surveillance and intervention in uncertain times." Journal of Adolescence 23 (4):463-476.

Kinsman, Gary. 1996. "'Responsibilty' as a strategy of governance: regulating people living with AIDS and lesbians and gay men in Ontario." Economy and Society 25 (3):393409. doi: 10.1080/03085149600000021.

Kitzinger, Jenny. 1995. "Qualitative Research: Introducing focus groups." BMJ 311 (7000):299-302. doi: 10.1136/bmj.311.7000.299.

Lawler, S. 2000. Mothering the Self: Mothers, Daughters, Subjects, Transformations (Routledge Hardcover): Routledge.

Levitas, Ruth. 2000. "Community, Utopia and New Labour." Local Economy 15 (3):188197.

Lupton, D. 1995. The Imperative of Health: Public Health and the Regulared Body. London: Sage.

Lupton, Deborah, and Jennifer Fenwick. 2001. "They've forgotten that I'm the mum': constructing and practising motherhood in special care nurseries." Social Science \& Medicine 53 (8):1011-1021. doi: http://dx.doi.org/10.1016/S0277-9536(00)00396-8.

Marshall, James D. 2001. "Varieties of Neo-liberalism: a Foucaultian perspective1." Educational Philosophy and Theory 33 (3-4):293-304. doi: 10.1111/j.14695812.2001.tb00272.x.

McCambridge, Jim. 2012. "Dealing Responsibly with the Alcohol Industry in London." Alcohol and Alcoholism 47 (6):635-637.

McDowell, Linda. 2000. "The Trouble with Men? Young People, Gender Transformations and the Crisis of Masculinity." International Journal of Urban and Regional Research 24 (1):201-209. doi: 10.1111/1468-2427.00243.

Measham, Fiona. 2002. "“Doing Gender" - "Doing Drugs": Conceptualising the Gendering of Drugs Cultures'." Contemporary Drug Problems 29 (2):335-373.

Measham, Fiona. 2004. "The decline of ecstasy, the rise of 'binge' drinking and the persistence of pleasure." Probation Journal 51 (4):309-326.

Measham, Fiona. 2008. "The turning tides of intoxication: young people's drinking in Britain in the 2000s." Health Education 108:207-222. 
Moore, Dawn, and Mariana Valverde. 2000. "Maidens at risk: 'date rape drugs' and the formation of hybrid risk knowledges." Economy and Society 29 (4):514-531. doi: 10.1080/03085140050174769.

Morgan, D. 2006. "The Crisis in Masculinity." In The Sage Handbook of Gender and Women's Studies, edited by K Davis, M Evans and J Lorber, 109-124. London: Sage.

Nairn, Karen, Higgins, J, Thompson, B, Anderson, M, \&amp; Fu, N. 2006. "'It's Just Like the Teenage Stereotype, You Go Out and Drink and Stuff': Hearing from Young People who Don't Drink." Journal of Youth Studies 9 (3):287 - 304.

Nilsen, Ann. 1999. "Where is the future? Time and space as categories in analyses of young people's images of the future." Innovation: The European Journal of Social Science Research 12 (2):175-194. doi: 10.1080/13511610.1999.9968596.

Olssen, Mark. 2005. "Foucault, Educational Research and the Issue of Autonomy." Educational Philosophy and Theory 37 (3):365-387. doi: 10.1111/j.14695812.2005.00127.x.

Peterson, A, and Bunton, R, ed. 1997. Foucault, Health, and Medicine. London / New York: Routledge.

Peterson, A., and Lupton, D. 1996. The New Public Health: Health and self in the age of risk. London: Sage.

Rich, Emma. 2012. "Beyond school boundaries: new health imperatives, families and schools." Discourse: Studies in the Cultural Politics of Education 33 (5):635-654. doi: 10.1080/01596306.2012.696498.

Robinson, Jude, and Amos, A. 2010. "A qualitative study of young people's sources of cigarettes and attempts to circumvent underage sales laws." Addiction 105 (10):18351843. doi: 10.1111/j.1360-0443.2010.03061.x.

Room, Robin. 2001. "Intoxication and bad behaviour: understanding cultural differences in the link." Social Science \& Medicine 53 (2):189-198.

Rose, Nikolas. 1996. "The death of the social? Re-figuring the territory of government." Economy and Society 25 (3):327-356. doi: 10.1080/03085149600000018.

Rúdólfsdóttir, A. G., and P. Morgan. 2009. "Alcohol is my friend': Young middle class women discuss their relationship with alcohol." Journal of Community \& Applied Social Psychology 19 (6):492-505. doi: 10.1002/casp.999.

Secretary of State for the Home Office. 2012. The Government's Alcohol Strategy CM8336. London: TSO (The Stationery Office).

Sheehan, M, \&amp; Ridge, D. 2001. "“You become really close...you talk about the silly things you did, and we laugh": The role of binge drinking in female secondary students' lives." Substance Use \& Misuse 36 (3):347-372. doi: doi:10.1081/JA100102630.

Silverman, D. 2013. Doing Qualitative Research: A Practical Handbook: SAGE Publications.

Simon, Jonathan. 1994. "In the Place of the Parent: Risk Management and the Government of Campus Life." Social \& Legal Studies 3 (1):15-45.

Skeggs, B. 1997. Formations of Class and Gender. London: SAGE Publications.

Smith, Karen. 2012. "Producing governable subjects: Images of childhood old and new." Childhood 19 (1):24-37.

Szmigin, I, Griffin, C, Mistral, W, Bengry-Howell, A, Weale, L, \&amp; Hackley, C. 2008. "Re-framing 'binge drinking' as calculated hedonism: Empirical evidence from the UK." International Journal of Drug Policy 19 (5):359-366.

Trnka, Susanna, and Catherine Trundle. 2014. "Competing Responsibilities: Moving Beyond Neoliberal Responsibilisation." Anthropological Forum 24 (2):136-153. doi: 10.1080/00664677.2013.879051. 
Wallace, Andrew. 2010. "New Neighbourhoods, New Citizens? Challenging 'Community' as a Framework for Social and Moral Regeneration under New Labour in the UK." International Journal of Urban and Regional Research 34 (4):805-819. doi: 10.1111/j.1468-2427.2009.00918.x.

Wallace, Andrew. 2014. "The English riots of 2011: Summoning community, depoliticising the city." City 18 (1):10-24. doi: 10.1080/13604813.2014.868161.

Ward, Sarah. 2012. "The Government's Alcohol Strategy: A view from the both ends of the world." Drugs: Education, Prevention, and Policy 19 (5):368-369. doi: 10.3109/09687637.2012.698426.

Woodman, Dan. 2009. "The mysterious case of the pervasive choice biography: Ulrich Beck, structure/agency, and the middling state of theory in the sociology of youth." Journal of Youth Studies 12 (3):243-256. doi: 10.1080/13676260902807227. 